\title{
Sustainability of Inclusive Education and COVID-19: Perspectives of Teachers and Parents of Children with Disability on Virtual Learning Platforms
}

\author{
Irene Vanderpuye \\ Department of Education and Psychology, University of Cape Coast \\ Martha-Pearl Okai \\ Department of Education and Psychology, University of Cape Coast
}

\begin{abstract}
This paper explores the perception of basic school teachers and parents of children with disability, regarding the feasibility of virtual learning platforms sustaining inclusive education during the COVID-19 pandemic and beyond. This has a wider implication internationally since education of the citizens of every country is inextricably linked to the attainment of United Nations Sustainable Development Goals, enshrined on inclusiveness. Inquiry into whether the use of virtual learning platform can balance the need for inclusive education and the health of a country's citizenry amidst the unrelenting pandemic and beyond is paramount. Qualitative research design with in-depth interview was employed for data collection. Thematic analysis was done using NVivo 12 software. Findings of the study reveals that the present virtual learning platforms by the Ministry of Education (MoE) and Ghana Education Service (GES) is an illusion as far as sustenance of inclusive education is concerned. MoE and GES should make the platform flexible and synchronous, involve special education teachers and provide parents with specialized training.
\end{abstract}

Keywords: Inclusive Education, Disability, Virtual Learning, COVID-19, Basic School, Ghana.

DOI: $10.7176 / \mathrm{JEP} / 12-8-10$

Publication date:March $31^{\text {st }} 2021$

\section{Introduction}

Effective implementation of inclusive ${ }^{1}$ education has been a difficult task for several countries including Ghana (Adarkwah, 2020; United Nations [UN], 2020; Upoalkpajor and Upoalkpajor, 2020). However, with the appearance of the new strain of coronavirus (nCov from genus Betacoronavirus) on the world scene, on 31 December 2019, some experts (Mohammed, 2020; UN, 2020, Global Voices, 2020) observed that the formidable challenges surrounding inclusive education has deepened, entrenching inequalities in accessibility to education. COVID-19 pandemic has altered the way we learn, live, and work (World Health Organization [WHO], 2019; Reimer et al., 2020; UN, 2020). On the throe of the second wave of the pandemic in November 2020, WHO (2020) reported that over 600,000 people are infected daily with about 10,000 dying every day from the disease. Its unsavoury impact is unrelenting, shattering hopes, dimming aspirations, and rending untold havoc in almost every sphere of human society.

Experts (Adarkwah, 2020; WHO, 2020; World Bank, 2020) indicated that due to its highly contagious nature everyone is susceptible to COVID-19. Hence, several countries have imposed super-strict measures and rules to curb its spread (Rasmitadila et al., 2020; Upoalkpajor and Upoalkpajor, 2020). For example, in the wake of the pandemic, a report by e-learning Africa (2020) and the United Nations (UN, 2020) revealed that, in over 190 countries, both pre-tertiary and tertiary schools were closed, disrupting the academic progress of 94 percent of the world's students' population. Studies indicated that Ghana was not left out, because about 9.2 million pupils in the basic schools as well as 0.5 million students in the tertiary levels were affected due to the closure of all schools across Ghana on 15 March 2020 (e-Learning Africa, 2020; Burgess and Sievertsen, 2020).

As a means of sustaining human capital and economic development (Mhlanga and Moloi, 2020; UNESCO, 2020; Dube, 2020), the government of Ghana introduced virtual learning platforms across the country. MoE and GES implemented the 'COVID-19 Emergency Support Provision of Distance and Remote Learning Systems Solutions' (Adarkwah, 2020; World Bank, 2020). The initiative provided a system where 1 million senior high school students learn through lessons broadcast on 'Ghana Learning Television' (GLTV). Likewise, over 8.2 million pupils in basic schools learn through Radio, TV and online platforms (UNICEF, 2020).

The introduction of the virtual learning platforms has generated controversy regarding its capability of sustaining inclusive education (Barden, 2017; Upoalkpajor and Upoalkpajor, 2020; Global Voices, 2020). Some studies claimed that virtual learning platform can sustain inclusive education. For example, Barden (2017)

\footnotetext{
${ }^{1}$ Inclusive education was enshrined on the 1994 Salamanca Statement, adopted by 25 international organizations and 92 governments, Ghana inclusive (Ainscow, Slee, and Best, 2019). The framework, according to Ainscow et al. (2019), stipulates that 'ordinary schools should accommodate all children, regardless of their physical, intellectual, social, emotional, linguistic and other conditions' (p. 2).
} 
indicated that virtual learning when well-structured can readily support learners irrespective of their condition. Guare et al. (2018) posited that television could be a veritable learning tool for pupils with Attention Deficit Hyperactivity Disorder (ADHD). However, the issue is different within Ghanaian context.

In her study, Mohammed (2020) indicated that MoE and GES virtual learning platforms were not designed to adequately accommodate learners with hearing impairment. Adarkwa (2020) indicated that ICT infrastructure is inadequate to sustain virtual learning for children with SEN. Other studies reveal that emphasis is often on how learners in rural communities will benefit from virtual learning platforms (Dube, 2020), ensuring psychosocial well-being of learners (Upoalkpajor and Upoalkpajor, 2020), attain continuity of education through Fourth Industrial Revolution (4IR) (Mhlanga and Moloi, 2020) and how virtual learning can be enhanced for students in higher education (Adarkwah, 2020). This study explores how learners with Special Educational Needs (SEN) can be accommodated on virtual learning platform.

The article is structured as follows: The first section provides a brief overview of inclusive education in Ghana while the second segment critically examined extant studies on inclusive education and virtual learning platforms. The third section outlines the research questions, followed by the fourth segment which entails methodology. The fifth section provides insight into data analysis results and discussions, while the sixth segment, which is the concluding part, covers the conclusion, recommendations, and limitations.

\section{The Concept of Inclusive Education}

It is estimated that there are about 200 million people suffering from disability in one way or another (WHO, 2011). Ghana Statistical Service (2012) indicated that over 8.3 million (3\%) of Ghana's population are disabled. These individuals, according to the Picton (2011), includes women, children, and aged persons. Principle of inclusive education dictates that children with disability should have access to quality education with a view to equipping them with relevant skills. Adewumi et al. (2017) indicated that children with SEN should learn in the same classroom with their peers without SEN.

In Ghana, several policy initiatives have been formulated with a view to successfully implement inclusive education. As one of the signatories to the Salamanca Statement (UNESCO, 1994), the Government of Ghana, alongside MoE and GES have rolled out several policies and ordinances to fast track the implementation of inclusive education. The 'Persons with Disability Act 2006 (Act 715)' was promulgated to protect, empower, and ensure full social participation of disabled people within Ghana's borders. Act 715 affirms the earlier policy by the Special Education Division of GES in 2005 to address the recurring segregation and inequality within Ghanaian educational landscape. The ordinance and policies pave way for inclusivity in education. Boi-Doku et al. (2019) posited that MoE and GES organized series of workshops and specialized training for supervisors, teachers, and instructors. As a result, in Ghana, inclusive education has been implemented in 48 districts with the establishment of 3,022 schools (Ministry of Education, 2015; UNICEF, 2019)

Inclusive education is enshrined on 'Sustainable Development Goal Four (SDG 4)' (UN, 2015), 'No Child Left Behind Act (Klein, 2020)' and 'Education Anytime, Anywhere for Everyone'. This means, children with disabilities and SEN should not be left behind or excluded from standard education. Inclusion in this regard is not a privilege rather a fundamental human right (Barden, 2017; UNICEF, 2019). With the implementation of COVID-19 Emergency Support Provision of Distance and Remote Learning Systems Solutions' to stem the tide of the pandemic among learners and teachers, virtual learning is seen as a means of sustaining continuity of educational objectives.

\subsection{Inclusive Education and Virtual Learning amidst COVID-19 Pandemic}

Though the implementation of inclusive education met with certain difficulties such as Teachers lacks requisite skills (Vuuro, 2017), inadequate training on how to teacher children with SEN (Ofori, 2018), poor teaching resources (Adedoyin and Okere, 2017) and poor ICT infrastructures (Adarkwah, 2020). The enumerated challenges mitigating full implementation of inclusive education worsens when the first two cases of COVID-19 were confirmed in Ghana on March 12, 2020. Literature revealed that social distancing as a means of curbing the spread of COVID-19 deters the usual person-to-person assistance rendered children with SEN. Hence, virtual learning platforms become a veritable means of educating children with SEN despite the dichotomy of opinion surrounding it.

For inclusivity and continuity, it is expected that this virtual learning platforms should accommodate children with all forms of disability including Traumatic Brain Injury and Behavioural Disorders (Barden, 2017; Adewunmi et al., 2017). Studies by Barden (2017) and Arthur-Nyarko and Kariuki (2019) shows that virtual learning is very beneficial and could accommodate all the categories of children with SEN. They indicated that at present, several e-Learning systems and assistive tools have been manufactured and designed to support disabled people in virtual learning and sustain inclusivity.

However, Lembani et al. (2019) indicated that virtual learning is not beneficial or useful under every context. For instance, Kizilcec and Halawa (2015) study discovered that learners in developing countries performed below 
average in e-learning mode of education in comparison to their counterpart in developed countries. Result of the comprehensive study by Alquahtani and Rajkhan (2020) on critical success factor on the use of virtual learning during COVID-19 pandemic, reveals that the system must be designed to meet multi-criteria. Paramount among these criteria is that the system should be synchronous and highly interactive, specialized training for teachers and pupils and team of experts to provide to support teachers and pupils on virtual learning platform programmes.

Perusal of these multi-criteria lend credence to the findings of a study by Mohammed (2020) that virtual learning platforms by MoE and GES are not designed to sustain inclusivity. Several disabled learners were not accounted for, hence find it difficult to access, navigate or derive any benefit from the platform. Adarkwah (2020) further indicated that prior to COVID-19, ICT infrastructure was very poor in the country, and there are several mitigating factors limiting effectiveness of virtual learning in Ghana as enumerated in the preceding section. Emergence of

COVID-19 worsens the situation and increased the lacuna or inequality existing between children with SEN and their counterparts. Hence, some experts concluded that sustaining inclusive education, at best, is a mirage within the Ghanaian setting. The next section outlines research problems with a view to ascertaining the feasibility of inclusivity within virtual learning platform in Ghana.

1. What are the provisions for inclusive education on MoE and GES virtual learning platforms?

2. What is the perception of teachers regarding sustainability of inclusive education through MoE and GES virtual learning platforms in Ghana?

3. What is the view of parents regarding how MoE and GES virtual learning platforms ensure continuity of inclusive classrooms for their children with SEN?

\section{Material and Method}

The study is underpinned by qualitative research method. Phenomenological approach was adopted for the purpose of conducting in-depth exploration, as well as comprehend meanings from groups and individuals associated with sustaining inclusive education on virtual learning platforms in Ghana, within the context of children with SEN (Maxwell, 2013; Creswell, 2013). Adoption of phenomenological approach was informed because of its propensity towards producing robust and rich findings (Mohajan, 2018)

\subsection{Instrument for Data Collection}

Data were elicited using semi-structured interview guides. The researchers, as the interviewers prepared a list of questions (closed and open ended) designed to address each of the research questions and guide the entire process of garnering useful information from participants (Creswell and Poth, 2018; Poth, 2019). The instruments were developed based on the raging debate by experts, stakeholders of education and parents regarding inclusive education and the newly introduced virtual learning platforms by MoE and GES in Ghana.

\subsection{Study Participants}

The target group for the study were basic school teachers involved in inclusive education, and parents of children with SEN in the Cape Coast Metropolis, being the citadel of education in Ghana (Yafetto and Osei-Bonsu, 2017; Yafetto et al., 2019). These groups of people are highly relevant to the focus of the study, with ample capacity of enriching the findings due to their familiarity and involvement with inclusive education. To achieve efficacy regarding qualitative research inquiry, Sauro (2017) posited that fewer participants, (5 to 25) are appropriate. As a result, using purposive and snowball sampling technique, ten participants were enlisted for the study, comprising five classroom teachers and five parents.

\subsection{Data Collection Procedure}

Due to COVID-19 pandemic and the need to maintain strict adherence to social distancing protocols, teachers and parents selected for the study were contacted online via conference call on mobile phone or video conferencing. The researchers made concerted effort so that those selected via snowball sampling technique meet the universe of the study (Mohajan, 2018; Creswell, 2018; Poth, 2019). The consent of participants was sought, and appropriate arrangement made for the individual interview. Guest et al. (2017) observed that 'individual interviews were effective at generating a broad range of items' (p. 693). This is very important since it will help in enriching the findings of the study. Though, the study intended to elicit information from ten participants, when saturation was attained with the inclusion of the $9^{\text {th }}$ participant, data collection ended. This agrees with Letham (2015) who emphasized that inclusion of participants should be stopped as soon as saturation point is reached.

The researchers recorded all the interviews and transcribed them verbatim to aid in-depth analysis of the collected data. To accurately transcribe the recorded interviews, each recording was replayed several times. The data was analysed using NVivo 12.0 software. Being a Qualitative Data Analysis (QSR) software, NVivo 12.0 eased the process of classifying, sorting and arranging transcribed data (QSR International, 2011). Analysis by NVivo 12.0 software was supplemented with manual examination of transcribed data and relevant documents. The 
researchers were able to detect emerging themes, patterns and trends and made appropriate inferences to resolve the three-pronged research questions. For ethical reasons, anonymity and confidentiality were observed.

\section{Data Analysis}

As stakeholders of education, parents and teachers' responses were explicit and insightful regarding the focus of the study. Analysis of the data provided insight into the implementation of MoE and GES COVID-19 Emergency Support Provision of Distance and Remote Learning Systems Solutions'. It also provided ample insight into features and mode of implementation of MoE and GES virtual learning platforms within the context of inclusivity on virtual learning platform (Lembani et al., 2019; Alquahtani and Rajkhan, 2020). Depicted in Table 1 are emergent themes and categories, as well as sub-themes and minor categories based on the responses of the participants. Rigorous analysis of the themes and sub-themes deepens knowledge on inclusive education and virtual learning.

In relation to platform environment, majority seven (7) out of the nine (9) participants indicated that the platform is not interactive (asynchronous). However, the remaining participants (2) felt otherwise. While one viewed it as synchronous, the other person referred to it as blended. The following excerpts are representative of the dominant view of the participants on the nature of MoE and GES virtual learning interface: 'so far, the one that I know of is the one that they upload not the live one, the one they the materials on' [A classroom teacher with 21 years of working experience]. Likewise, another parent with four years working experience stated: 'normally they don't interact with people on the platform'.

Concerning meeting students' needs, only one (1) of the participants agreed that the platform meet the varied needs of pupils. The remaining participants (8) disagree and some of their comments are highlighted below. After responding ' $n o$ ' to the question on whether the platform meet pupils' needs, a graduate teacher with 21 years of working experience stated: '...those who have that hearing impairment can't access, even those having visual impairment will have it a bit difficult accessing it'. Another teacher with M.Ed as his educational qualification stated: 'it is not meeting the needs...because the necessary preparation that should have been done was not fully done.'

Regarding inclusivity support, participants made choices in connection with the question on whether the platform can accommodate all the pupils irrespective of pace of academic achievement and disability, almost all (8) the participants indicated that it does not support inclusivity. One of the parents with 25 years of working experience and a child with disability remarked: 'with the online, he can't use it at all'. A graduate teacher with two years working experience said: '...for now, I will say we have to work on it very well because looking at even this school and the number of computers that we have, it's a problem, even to access the internet.'

Providing their opinion on ICT infrastructure, all (9) the participants agreed that there is limited infrastructure as far as ICT is concerned. A classroom teacher with 12 years of working experience stated: 'yes, technological know-how because with the ICT, we don't have machines to practice with the kids and at times you will be working, and you need to change different networks...'. One of the parents with four years working experience and Mphil as his level of education intimated: 'I think government can support in terms of making the internet available to everybody'. One of the classroom teachers with 13 years working experience stated: 'look at the advance countries, the children have access to computers... but here is the case that in Ghanaian setting, we don't have.'

Participants made their opinion known in connection with platform liaison team when responding to issues concerning ready support for users of the platform. Majority (7) of the participants indicated that management team for the platform are not readily accessible hence some of the teachers must get support from relatives. For example, one of the parents with six years working experience and a child with disability stated: 'because he won't get anyone to help him but if had gotten help, he would have been able to'.

Thorough study of the excerpts reveals that most of the participants see the provisions on

the virtual learning platform as inadequate to support or sustain inclusivity. For example, participants indicated that though the platform is very good at this time of COVID-19, it is not interactive and does not allow teachers to monitor pupils' progress. One of the graduate teachers with 21 years of working experience noted: 'so far, the one that I know of is the one that they upload not the live one'. One female teacher with 12 years of working experience categorically stated that the platform 'its asynchronous'. She further stated: 'the thing is even time bound so... you cannot discuss'.

Participants indicated that children with disability and others with low socioeconomic background are not benefitting from the platform. Typical of such opinion is the statement of a parent (mother) with 25 years working experience, she stated: '...there is this learning programme on the FM station every Friday; I sit him down for him to listen but even with that when you ask him question after that, he can't answer'. Another parent (Father) with 16 years working experience stated: 'I think they are doing their best as at now but some are also lagging behind example is my boy, he cannot access the online teaching, he wouldn't understand what they are even doing...'. 


\subsection{Result and Discussion}

Findings of the study are inconsistent with the result of the comprehensive study by Alquahtani and Rajkhan (2020) regarding inherent features of a virtual learning platform designed to sustain inclusivity. Alquahtani and Rajkhan indicated that such platform should support inclusivity, accommodate the needs of all pupils, provision should be made for team of experts or stakeholders to facilitate access to the platform.

In brief, findings of the study revealed that the provisions on MoE and GES virtual learning platform does not support inclusivity because the environment is asynchronous with no avenue for interaction, it does not meet the needs of all pupils, does not accommodate children with disability. Result of the study showed that ICT infrastructure is still very low making the platform inaccessible to several pupils and there are few liaison team or management team to provide real-time support for pupils or their parents.

The teachers were very explicit in their responses concerning their feelings on the virtual learning platforms provided by MoE and GES. Relevant excerpts underscoring their perception of the programme are highlighted below. In their response on familiarity with the platforms, majority four (4) indicated they are familiar with the platform as exemplified in the excerpt below by a teacher with 13 years working experience: 'yes, I'm familiar'.

However, teachers are divided on viability of the platform for inclusivity. While three (3) teachers strongly believe that upon improvement of the platform, it will be useful in sustaining inclusive education, the remaining two (2) disagrees citing the poor level of ICT infrastructure in the country and other limiting factors as typified in the following excerpt retrieved from the comment of a classroom teacher with 21 years of working experience: 'as it stands now, I don't think so...because most of those having the challenges...don't have the resources to access this type of platform'. Notwithstanding, another teacher with 13 years of working experience disagrees by stating: 'when we talk about inclusive learning, we are also talking about involvement of children with special needs so definitely if those people are actually trained in that line, it will help.'

The comment of the two teachers underscores the fact that presently, there are so many limiting factors that makes virtual learning within the Ghanaian context to be very difficult in meeting the individual needs of every pupil. For example, the first excerpt showed that even when the platform has the requisite features, many students cannot access it because they 'lack resources'. Such resources involve money to buy data, non-existence of electricity in their neighbourhood being a rural area and lack of adequate requisite skill in accessing the platform.

Notwithstanding the teacher with 21 years of working experience indicated that: 'this virtual learning is a very necessary means of containing it all so long as you give the kids...opportunity to acquire some basic understanding'. In effect, he is of the opinion that enhancing virtual learning platforms alongside intensive training is far better than visiting pupils in their homes.

Both participants are correct to a certain extent because there are external factors apart from the platform limiting its sustainability within the Ghanaian context. However, as the second participant indicated, with improved platform and heightened awareness and online training for pupils and their parents, it can be achieved. This finding is consistent with the results of several studies (Barden, 2017; Upoalkpajor and Upoalkpajor, 2020; Global Voices, 2020) that the government of Ghana should work on both the internal and external factors limiting the capacity of the platform to accommodate pupils and their needs. Perception of teachers on the MoE and GES virtual learning platform in connection with inclusivity is summarized in Figure 1.

A closer study of the chart reveals that though most of the teachers are aware of the platform, several lacks requisite skills and training to manipulate it. The chart revealed that majority of the pupil lacks knowledge of how to access the platform or benefit academically from it. Information in Figure 1 coincides with the focus of the study that virtual learning within Ghanaian context, at the present time, is not possible, perhaps in the nearest future, it will be possible provided the government develop novel approach to implementing virtual learning.

In a nutshell, teachers perceived the current MoE and GES virtual learning platform as serious lacking inclusivity at the present time. However, they are convinced that with

improvement of ICT infrastructure, regular and result-oriented training, and ample provision of experts in every school to provide real-time support for both teachers and pupils (including their parents where necessary).

As affiliates of inclusive learning institutions, all the parents interviewed had high-level experience on issues involving inclusive education and provided insightful comments. Careful analysis of their responses yielded four sub-themes, namely: 1) ease of access, 2) home environment, 3) child quality, and 4) relevance of virtual learning platform to their child. The pictorial illustration in Figure 2 vividly portrays the aggregate responses of the parents on the MoE and GES virtual learning platform and sustainability of inclusive education.

In-depth analysis of the chart in Figure 2 vividly portrays the feelings of parents on the current MoE and GES virtual learning platforms. Only one (1) of the parents agreed that there is ease of access on the platform, majority (3) disagrees. The following excerpts by one of the parents with 16 years working experience underscores the dominant feelings among parents regarding ease of access 'he is not, he doesn't take part'. The only parent that affirms ease of access on the platform later stated: 'most of the time he is able to get on the platform when I'm around'. When asked whether the child can access the platform alone, he responded: 'for now, not yet'. This confirms the submissions of the other parents that the platform is not readily accessible. 
Home environment refers to whether the platform can accommodate pupils in all types of home settings ranging from rural to urban areas. There is dichotomy of opinion among parents as highlighted in the following excerpts. A parent with 25 years of working experience stated: 'he sits and just listens but even with that he can't answer questions after listening..., it does not help my ward'. Based on his four years of working experience as an Mphil holder in special education,

one of the parents stated: 'yes, he is benefitting...there is some work for him to do...'

A careful study of the two excerpts showed that while some children are benefitting others are not. From our perspective, the issue revolves around child quality. By child quality, we mean inherent capabilities of the child. This was covered by the third sub-theme 'Child quality'. As depicted in the chart, only one (1) parent agreed that the platform can accommodate children varying qualities. This is typified by the following comment of a parent with six years working experience: 'he is not that clever, and he hasn't got anyone who will teach him'. Another parent with 16 years working experience posited: 'I think they are doing their best as at now, but some are also lagging behind example is my boy, he cannot access the online teaching'.

The chart revealed that most (3) of the parents disagreed that the virtual learning platform,

is relevant to their wards at this period of the COVID-19 pandemic. One of the parents complained: 'he cries when he watches because he gets confused. When you ask him question, he won't talk.' In effect, at the present, the virtual learning platform is not relevant to the needs of most of the children with SEN. This is consistent with the findings of Mohammed (2020) that learners with hearing impairment are not benefitting from the newly launched platform.

However, result of the study is inconsistent with the findings of Bardin (2017) and Arthur-

Nyarko and Kariuki (2019) that virtual learning can accommodate the needs of the varied categories of children with SEN. This finding is relevant in view of Adarkwah (2020) and Mohammed (2020) that the current virtual learning platform is inadequate for sustaining inclusivity. In summary, the study reveals that the MoE and GES virtual learning platform was not designed with ease of access for every pupil, cannot accommodate the varying socioeconomic and academic situation of pupils, and pupils' physical conditions, hence it is not relevant to several pupils at this time.

\section{Conclusions}

Critical analysis of the emergent themes and subthemes associated with this study reveals that the provisions on the recently launched virtual learning platforms by MoE and GES is inadequate to support inclusive education. Perceptions of the selected teachers and parents revealed that the design of the platform was not in compliance with the Salamanca Statement (UNESCO, 1994) and the promulgated ordinance tagged 'Persons with Disability Act 2006 (Act 715) of Ghana. These statement and ordinance stipulated the inclusion of all learners with disabilities in mainstream schools, so that they can interact with peers without disability. It is envisaged that inclusivity will boost children with SEN's self-esteem and fast track their academic achievement, instead of being isolated in a separate facility or separate virtual learning platform.

Virtual learning platform appeared as the panacea for managing the educational system in

Ghana. However, critical examination of the recently launched virtual learning platforms by MoE and GES, alongside the perspectives of teachers and parents on its viability, revealed that the platform is seriously lacking as far as meeting the needs of children with SEN are concerned. Teachers and parents agreed that the present platform is an illusion and cannot sustain inclusive education.

Suggestive future virtual learning platform by MoE and GES could include arrangement for special education teachers to participate in the programme. Essentially, the virtual learning platform should be re-engineered or redesigned to allow for interaction, in similar fashion with some private institutions in the country. Both regular and special education teachers on synchronous platform can sustain inclusivity.

Flexible and specialized online training should be provided teachers and parents (or

someone designated by parents), on how to use the synchronous platform so that these stakeholders can, in turn, teach their wards including those with SEN. Since COVID-19 restrictions does not affect parents and children interaction, parents could help their wards at home and provide real-time feedback to teachers and other instructors through phone calls.

The study comprises a small representation of teachers and parents within the basic school context using the MoE and GES virtual learning platform. The study only utilised an interview guide for data collection. Future research could encompass the students, teachers, and parents to rigorously examine the same topic. Likewise, questionnaire and focus group discussions with mixed methodology as the research design can be used to critically examine the same topic in Accra metropolis, being the technological capital of the country.

\section{References}

Adarkwah, M. A. (2020). I'm not against online teaching, but what about us?: ICT in Ghana post COVID-19. Education and Information Technologies, https://doi.org/10.1007/s 10639-020-10331-z. 
Adewumi, T.M., Rembe, S., Shumba, J. and Akinyemi, A., (2017). 'Adaptation of the curriculum for the inclusion of learners with special education needs in selected primary schools in the Fort Beaufort District', African Journal of Disability no. 6: a377. https://doi.org/ 10.4102/ajod.v6i0.377

Aljaraideh, Y., and Bataineh, K. A. (2019). Jordanian students' barriers of utilizing online learning: A survey study. International Education Studies, no. 12(5): 99-108.

Arthur-Nyarko, E., and Kariuki, M. G. (2019). Learner access to resources for eLearning and preference for eLearning delivery mode in distance education programmes in Ghana. International Journal of Educational Technology, no. 6(2): 1-8.

Barden, O. (2017) Disability media studies, Disability and Society, 33:10,1672-1674, https://doi.org/10.1080/09687599.2018.1541611.

Bean, M. V., Aldredge, T., Chow, K., Fowler, L., Guaracha, A., McGinnis, T., Parker, L., Saez-Kleriga, G. (2019). Effective practices for online tutoring. Sacramento: Academic Senate for California Community Colleges. https://files.eric.ed.gov/fulltext/ED601995.pdf

Boi-Doku, A., Twumasi-Ankrah, K. and Hanson, R. (2019). Interpretation of inclusive education practices in science at a basic school. African Journal of Educational Studies in Mathematics and Sciences, Vol. 15, No. 2, pp. 15-22.

Boi-Doku, A. (2019). The effect of computer assisted instruction (CAI) on students' cognitive achievement in chemical bonding. a case study of schools in the Kwahu east district of Ghana. International Knowledge Sharing Platform, Vol. 10, No. 20, pp. 54-63.

Burgess, S. and Sievertsen, H. H. (2020). Schools, skills, and learning: the impact of COVID-19 on education. https://voxeu.org/article/impact-COVID-19-education.

Creswell, J. W. (2018). Research design: qualitative, quantitative, and mixed methods approaches (5th ed.). Los Angeles: SAGE.

Creswell, J. W., and Poth, C. N. (2018). Research design: principles and methods. Education Services Publication.

Dube, B. (2020). Rural online learning in the context of COVID-19 in South Africa: evoking an inclusive education approaches. Multidisciplinary Journal of Educational Research, no. 10(2): 135-157.

eLearning Africa (2020). Press release: COVID-19 'an opportunity' say African Educators in major new survey. https://www.elearning-africa.com/main/resources/press releases /ELA. php?year=2020andpr id=403.

Ghana Statistical Service (2012). '2010 Population and Housing Census. '. Accra: Ghana Statistical Service.

Global Voices (2020). How COVID-19 affects education for people with disability in Ghana. https://globalvoices.org/2020/07/03/how-COVID-19-affects-education-for-people-with-disabilities-inghana/.

Guare, R., Sprinkle, K., and Kulman, D. (2018). Executive skills in children and adolescents: a practical guide to assessment and intervention. Guilford Publications.

Kizilcec, R. F., and Halawa, S. (2015). Attrition and achievement gaps in online learning. In Proceedings of the Second (2015) ACM Conference on Learning@, Scale(pp. 57-66). ACM

Lembani, R., Gunter, A., Breines, M., and Dalu, M. T. (2019). The same course, different access: the digital divide between urban and rural distance education students in South Africa. Journal of Geography in Higher Education, no. 44(1): 70-84. https://doi.org/ 10.1080/03098265.2019. 1694876

Maxwell, J.A. (2013). Qualitative research design: an interactive approach. Thousand Oaks, CA: SAGE Publications, Inc. (pp. 135-136).

Mhlanga, D. and Moloi, T. (2020). COVID-19 and the digital transformation of education: what we are learning in South Africa. file://C:/Users/pc/AppData/Local/ Temp/preprints 202004.0195.v1.pdf.

Ministry of Education, Science and Sports. (2003). Education strategic plan 2003 to 2015. MOESS.

Ministry of Education. (2015). Inclusive education policy. MOE.

Mohajan, H. K. (2018). Qualitative research methodology in social sciences and related subjects. Journal of Economic Development, Environment and People, Vol-7, Issue 01, pp. 23-48.

Mohammed, W. F. (2020). What COVID-19 reveals about educational inequality in Ghana. https:/www.aljazeera.com/features/2020/4/7/-what-COVID-19-reveals-about-educational-inequality-inghana.

Ofori, E. A. (2018). Challenges and opportunities for inclusive education in Ghana. Unpublished thesis submitted to the University of Iceland.

Picton, A. (2011). 'Denying Ghana's disabled their rights. the disability act: 5 Years on'. Accra, Ghana: CHRI Africa. http://chriafrica.blogspot .no/2011/06/denying-Ghana's-disabled-their-right.

Poth, C. N. (2019). Rigorous and ethical qualitative data reuse: potential perils and promising practices. International Journal of Qualitative Methods, Vol. 18, No. 1, pp. 1-4.

Rasmitadila, R., Aliyyah, R. R., Rachmadtullah, R., Samsudin, A., Syaodih, E., Nurtanto, M., and Tambunan, A. R. S. (2020). The perceptions of primary school teachers of online learning during the COVID-19 pandemic period: a case study in Indonesia. Journal of Ethnic and Cultural Studies, Vol. 7, No. 2, pp. 90-109. 
Reimer, J. R., Ahmed, S. M., Brintz, B., Shah, R. U., Keegan, L. T., Ferrari, M. J., and Leung, D. T. (2020). medRxiv : the preprint server for health sciences, 2020.07.07.20148510. https://doi.org/10.1101/2020.07.07 .20148510.

UNICEF (2020). Global COVID-19 response. https://www.unicef.org/appeals/COVID-19.

UNESCO. (2020). COVID-19 educational disruption and response. https://en.unesco. org/covid19/educationresponse.

UNESCO. (2017). Overcoming exclusion through inclusive approaches in education. a challenge and vision. Conceptual paper. UNESCO.

UNESCO. (1994). The Salamanca statement and framework for action on special needs education. Adopted by the World Conference on Special Needs Education: Access and Quality. Salamanca, Spain, 7-10 June 1994. UNESCO.

United Nations (2020). Policy brief: education during COVID-19 and beyond. https://www.un.org/development/desa/dspd/wp-content/uploads/sites/22/2020/08/sg_policy_brief_COVID19_and_education_august_2020.pdf.

Upoalkpajor, J.-L. N., and Upoalkpajor, C. B. (2020). The impact of COVID-19 on education in Ghana. Asian Journal of Education and Social Studies, no. 9(1): 23-33. https://doi.org/ 10.9734/ajess/2020/v9i130238.

World Bank (2020). The global economic outlook during the COVID-19 pandemic: a changed world. https://www.worldbank.org/en/news/feature/2020/06/08/the-global-economic-outlook-during-the-COVID19-pandemic-a-changed-world.

World Health Organization (2020). Single-day global increases in cases. https:/www.bbc.com/news/world53454558

World Health Organization (2011). World report on disability. https://www.who.int/disabilities /world_report/2011/report.pdf.

Vuuro, E. (2017). Barrier of inclusive education: the case of Wenchi senior high school in the Wenchi municipality. Unpublished master's thesis submitted to Kwame Nkrumah University of Science and Technology (KNUST).

\section{APPENDICES}

Table 1: Themes and Sub-themes from the Data

\begin{tabular}{ll}
\hline Major Themes (Category) & Sub-Themes (Minor Category) \\
\hline Inclusivity on MoE and GES Virtual Learning & $\bullet$ Platform environment \\
Platform & $\bullet$ Meet students' needs \\
& $\bullet$ Inclusivity support \\
& $\bullet$ ICT infrastructure \\
Teachers' Perspective on MoE and GES Virtual & $\bullet$ Platform Liaison team \\
Learning Platform & - Viability for inclusivity \\
& $\bullet$ Student quality \\
Parents' Perspective on MoE and GES Virtual & $\bullet$ Teacher quality \\
Learning Platform & $\bullet$ Ease of Access \\
& $\bullet$ Child quality \\
& $\bullet$ Relevance to Child \\
\hline
\end{tabular}

Source: Researchers' Construct (2021) 


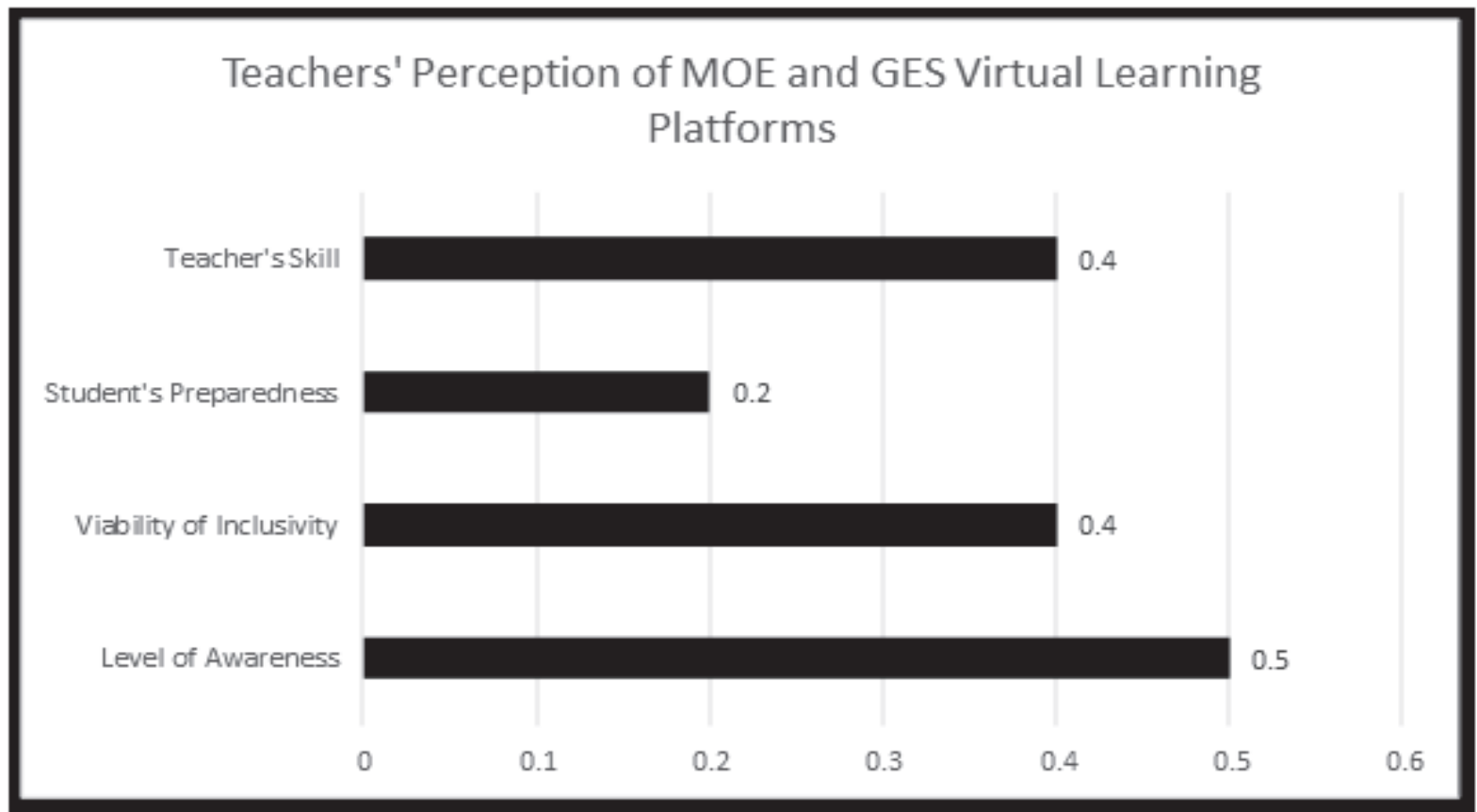

Figure 1: Teachers' Perception of Virtual Learning Platform by MoE and GES Source: Researchers' Construct (2021)

\section{Parents Perspective on MOE and GES \\ Virtual Learning Platforms}

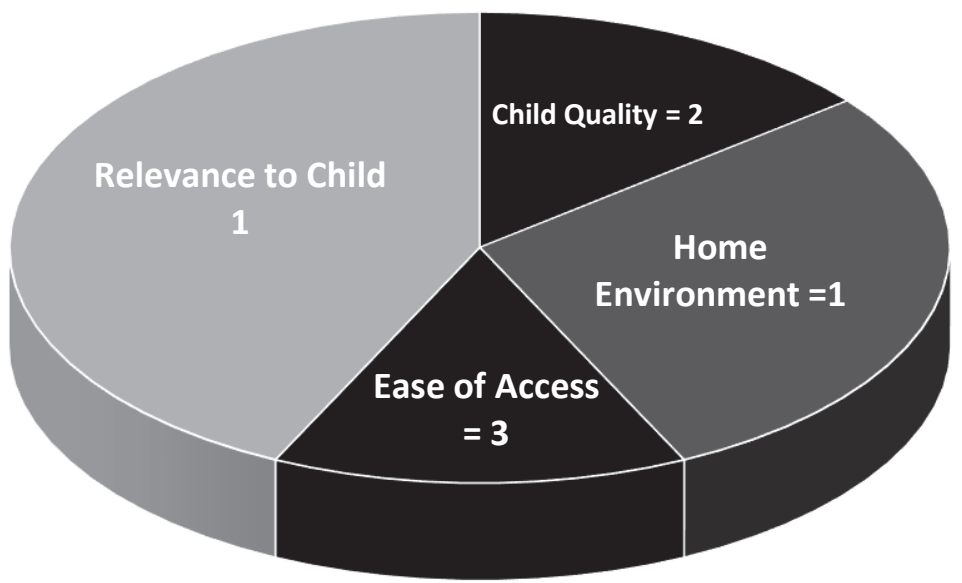

Figure 2: Parents' Perception of Virtual Learning Platform by MoE and GES

Source: Researchers' Construct (2021) 